\section{Apocalypse: the end of antibiotics?}

\author{
Phil Wiffen
}

Oxford dictionaries define apocalypse as 'an event involving destruction or damage on a catastrophic scale'.

In October this year, England's chief medical officer, Sally Davies, reported that the world was facing a postantibiotic apocalypse that will lead to the end of modern medicine as we know it. I would not normally write another editorial on antibiotic resistance so soon after the call in the November 2017 issue, which reminded pharmacists of their gatekeeper role in the use of antimicrobials, but such radical comments have to be taken seriously.

The 2017 English Surveillance Programme for Antimicrobial Utilisation and Resistance report ${ }^{1}$ highlights the issues facing England and also has useful information for Europe. The data make worrying reading. In 2016 the most common cause of bloodstream infections was Escherichia coli, where 41\% were resistant to co-amoxiclav, the most common antibiotic used. Twenty per cent of these were resistant to at least one other key antibiotic. Antimicrobial resistance was common in more than one million urinary tract infections, and of these 34\% were resistant to trimethoprim. Current public health guidelines recommend the use of nitrofurantoin, where resistance was seen at $3 \%$.

There is some evidence of a reduction in prescribing. Overall prescribing has reduced by 5\% between 2012 and 2016. In general practitioner practices the number of prescriptions decreased by $13 \%$ in the same period. A reduction in total antibiotic prescribing in hospitals was seen in 2015, but this was not maintained in spite of the widespread appointment of specialist antimicrobial pharmacists.

The report also has some information on resistance to antifungal agents, with widespread resistance of Aspergillus to amphotericin B and some resistance to itraconazole.

While the report is UK-focused, there are useful data and maps illustrating the problem for European countries. E. coli resistance to quinolones is running at over $50 \%$ in many eastern and southern

Correspondence to Professor Phil Wiffen, Pain Research Unit, Churchill Hospital, Oxford OX3 7LE, UK; phil.wiffen@ndcn.ox.ac.uk
European countries. A similar increase is reported for Klebsiella pneumoniae resistance to carbapenems, but in fewer countries, mainly Greece and Italy.

Pharmacists need to be aware of any national initiatives, such as one from Germany referenced below. ${ }^{2}$

Resources looking at the wider picture in Europe are available. ${ }^{3-5}$ Readers need to be familiar with the work of the European Centre for Disease Prevention and Control. Good information alone is not sufficient, action is needed.

This has to be another call for hospital pharmacists and hospital pharmacy managers to take this issue seriously or we risk having a future generation for whom antimicrobials are ineffective both for active treatment and for prophylaxis. What can pharmacists do?

First we need to take personal responsibility and ask: "What am I or my pharmacy doing to improve control of antimicrobials?'

Second there is a need to ensure that an up-to-date antimicrobial policy is available and implemented, with pharmacists playing their part on the policy committee.

An updated Cochrane review ${ }^{6}$ concluded: 'we found high-certainty evidence that interventions are effective in increasing compliance with antibiotic policy and reducing duration of antibiotic treatment. Lower use of antibiotics probably does not increase mortality and likely reduces length of stay'. That's an important message!

A different Cochrane review ${ }^{7}$ looking at the concept of delaying antibiotic prescriptions concluded: 'Where clinicians feel it is safe not to prescribe antibiotics immediately for people with respiratory infections, no antibiotics with advice to return if symptoms do not resolve is likely to result in the least antibiotic use while maintaining similar patient satisfaction and clinical outcomes to delaying prescription of antibiotics.'

A paper published in 2016 from a multidisciplinary group including hospital pharmacists points to some useful resources around antimicrobial stewardship policies from five countries. The paper has tables pointing to guidelines and online courses that could be usefully employed to increase skills. The paper suggests the need for those involved in antibiotic stewardship to reach out more widely to share experiences and education, as well as collaborate in research and publication. Perhaps there is a role for the European Association of Hospital Pharmacists (EAHP) to develop a sharing portal in addition to the EAHP resources already available. ${ }^{8}$

The action required is almost certainly a series of small steps that will reduce the threat of an antibiotic apocalypse. This journal would certainly welcome papers describing such actions.

\section{Competing interests None declared.}

Provenance and peer review Commissioned; internally peer reviewed.

(C) European Association of Hospital Pharmacists (unless otherwise stated in the text of the article) 2018. All rights reserved. No commercial use is permitted unless otherwise expressly granted.

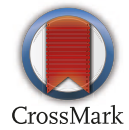

To cite Wiffen P. Eur J Hosp Pharm 2018;25:1.

Eur J Hosp Pharm 2018;25:1.

doi:10.1136/ejhpharm-2017-001464

\section{REFERENCES}

1 Public Health England. English surveillance programme for antimicrobial utilisation and resistance (ESPAUR) Report. 2017 https://www.gov.uk/government/ publications/english-surveillance-programmeantimicrobial-utilisation-and-resistance-espaur-report (accessed 3 Nov 2017).

2 de With K, Allerberger F, Amann S, et al. Strategies to enhance rational use of antibiotics in hospital: a guideline by the German Society for Infectious Diseases. Infection 2016:44:395-439.

3 European Centre for Disease Prevention and Control. Materials for professionals in hospitals and other healthcare settings, such as long-term care facilities, who have different roles and influence in the use of antibiotics in such settings. https://antibiotic.ecdc.europa.eu/en/ prescribers/materials-professionals-hospitals-and-otherhealthcare-settings (accessed Nov 2017).

4 European Centre for Disease Prevention and Control. Annual report of the European Antimicrobial Resistance Surveillance Network (EARS-Net). 2016 https://ecdc. europa.eu/sites/portal/files/documents/AMR\%202016_ Final-with-cover-for-web-2017.pdf (accessed Nov 2017).

5 European Centre for Disease Prevention and Control. Summary of the latest data on antibiotic consumption in the European Union. $2017 \mathrm{https}: / /$ ecdc.europa. eu/sites/portal/files/documents/EAAD_ESAC-Net_ Summary2017.pdf (accessed Nov 2017).

6 Davey P, Marwick CA, Scott CL, et al. Interventions to improve antibiotic prescribing practices for hospital inpatients. Cochrane Database Syst Rev 2017:2:CD003543.

7 Spurling GK, Del Mar CB, Dooley L, et al. Delayed antibiotic prescriptions for respiratory infections. Cochrane Database Syst Rev 2017;9:CD004417.

8 European Association of Hospital Pharmacists. EAHP policy statement on antimicrobial resistance. http:// www.eahp.eu/practice-and-policy/EAHP-statements (accessed Nov 2017). 